Check for updates

Cite this: RSC Adv., 2019, 9, 19620

\title{
Mn promotes the rate of nucleation and growth of precipitates by increasing Frenkel pairs in $\mathrm{Fe}-\mathrm{Cu}$ based alloys
}

\author{
Tong Li, ${ }^{a}$ Yaoping Xie, (D) *a Xiaojiao Wang, ${ }^{\text {b }}$ Qin Shen, ${ }^{c}$ Jiabao Li, ${ }^{a}$ Haibo Guo, ${ }^{d}$ \\ Jingxiang $\mathrm{Xu}$ (iD) ${ }^{\mathrm{e}}$ and Wenqing $\mathrm{Liu}^{* a}$
}

$\mathrm{Fe}-1.0 \mathrm{Cu}$ (at\%) and $\mathrm{Fe}-1.2 \mathrm{Cu}-2.2 \mathrm{Mn}$ alloys aged at $450{ }^{\circ} \mathrm{C}$ for $0.25 \mathrm{~h}, 1 \mathrm{~h}, 2 \mathrm{~h}$, and $16 \mathrm{~h}$ after solution treatment at $900{ }^{\circ} \mathrm{C}$ for $2 \mathrm{~h}$ are investigated to reveal the role of the addition of $\mathrm{Mn}$ on the $\mathrm{Cu}$ precipitates in $\mathrm{Fe}-\mathrm{Cu}$ based alloys. Density functional theory (DFT) total energy calculations on point defects and their influence on $\mathrm{Cu}$ precipitates are also performed to understand the nucleation and growth of $\mathrm{Cu}$ precipitates. Experiments show that addition of $\mathrm{Mn}$ can slightly increase the aging peak hardness by $10 \mathrm{HV}$; by using atom probe tomography (APT) and optical microscopy, we identify that the increase in hardness derives from both grain refinement and the increase of number density of precipitates. DFT calculations show that $\mathrm{Mn}$ increases the formation possibility of Frenkel pairs, i.e., atomic vacancy and self-interstitial atoms, and these two types of defects both serve as nucleation sites of $\mathrm{Cu}$ precipitates, resulting in the increase of the nucleation centers number density, which is consistent with our APT experiments on the very initial stage of aging. Moreover, calculated results show that Mn increases the density of atomic vacancies and promotes the evolution rate of $\mathrm{Cu}$ precipitates, which accounts for our APT experiments where precipitates in Fe-Cu-Mn grow more quickly than in Fe-Cu. Finally, we also discuss the relationship between $\mathrm{Mn}$ content in reactor pressure vessel steels and its irradiation damage effects.

Received 30th April 2019

Accepted 11th June 2019

DOI: $10.1039 / c 9 r a 03226 f$

rsc.li/rsc-advances
Many alloying elements were confirmed to be able to influence the formation of $\mathrm{Cu}$ precipitates. The interaction between alloying elements and $\mathrm{Cu}$ precipitates is very complicated. On the one hand, the alloying elements can promote the formation of $\mathrm{Cu}$ precipitate and lead to multicomponent $\mathrm{Cu}$-rich precipitates. ${ }^{1-3,7,9}$ On the other hand, the many other alloying elements can be clustered in the $\mathrm{Cu}$ precipitates or at the interface between $\mathrm{Cu}$ precipitates and matrix, such as NiAl phase, ${ }^{7-9,26-28}$ G phase, etc. ${ }^{29,30}$ Usually, HSLA steels are composed of many alloying elements, and the microstructure and mechanical properties have been well studied. For example, the evolution of precipitates in Northwestern University copper alloyed serveries steels $(\mathrm{NUCu})$ has been well characterized, and the mechanical properties, such as hardness were also examined under different treatments. ${ }^{1-3,9}$ For RPV steels, it is very fortunate that many data on Cu-rich clusters in steels under neutron irradiation have been reported, ${ }^{16,17,19,21,31}$ though the data generally are rare for many other materials under neutron irradiation.

To understand the role of different elements on the $\mathrm{Cu}$ precipitates, many works were dedicated to reveal the interaction between alloying elements and $\mathrm{Cu}$ precipitates. It has been confirmed that $\mathrm{Mn}$ has obviously interaction with $\mathrm{Cu}$ precipitates. It segregates at the $\mathrm{Cu}$ precipitates, ${ }^{1}$ and also induces the formation of Mn clusters in steels alloyed with the composition of $\mathrm{Cu}, \mathrm{Ni}, \mathrm{Si}$, and $\mathrm{Mn} \cdot{ }^{25}$ Furthermore, there is a combinative 
effect of $\mathrm{Mn}$ and $\mathrm{Cu}$ contents on embrittlement of RPV steels induced by neutron irradiation.

Since $\mathrm{Mn}$ and $\mathrm{Cu}$ have combined effect on the neutron irradiation induced embrittlement, Glade et al. ${ }^{20}$ investigated the influence of $\mathrm{Mn}$ on $\mathrm{Cu}$ precipitate in model RPV steel by using positron annihilation spectroscopy and small-angle neutron scattering. They found that the effect of $\mathrm{Mn}$ is to reduce the size and increase the number density of precipitates in the $\mathrm{Fe}-\mathrm{Cu}-\mathrm{Mn}$ alloy relative to the $\mathrm{Fe}-\mathrm{Cu}$ alloy. Later, Miller et al. ${ }^{21}$ using atom probe tomography and small-angle neutron scattering (SANS) experiments, also confirmed that Mn can increase number density of precipitates, and it was approximately an order of magnitude higher in the $\mathrm{Fe}-\mathrm{Cu}-\mathrm{Mn}$ alloy compared to $\mathrm{Fe}-\mathrm{Cu}$ alloy.

As a common element in steels, it was found very early that $\mathrm{Mn}$ increases $\mathrm{Cu}$ precipitation hardening effects. However, most of the investigations about the effect of $\mathrm{Mn}$ were performed in alloys containing $\mathrm{C}, \mathrm{Si}$ and $\mathrm{Al}$ at non-negligible levels, and therefore the hardening effect cannot be confirmed to be only from Mn. Shabadi et al. ${ }^{32}$ performed a careful preparation of model alloys to elucidate the true effect of $\mathrm{Mn}$, and they confirmed this effect. It was found clearly that the addition of Mn significantly increases the kinetics of aging, while its effect on the magnitude of precipitation strengthening is only marginal. In addition, the effect of $\mathrm{Mn}$ on the over-aging stage was also identified: Mn reduces increment of aging hardening in the region of over aging.

In the theoretical side, extensive investigations by using density functional theory (DFT) are performed to understand $\mathrm{Cu}$ precipitates in steels; many aspects related to magnetism, thermal dynamics, kinetics of this system have been revealed. It has been found that the dependence of phase separation tendency between $\mathrm{Fe}$ and $\mathrm{Cu}$ on temperature is more related to the magnetic phase transition compared to vibrational contribution. ${ }^{33-36}$ The calculations of elastic properties of bulk $\mathrm{FeCu}$ phase revealed that only $\mathrm{FeCu}$ with $\mathrm{Cu}$ content below $50 \%$ is mechanically stable ${ }^{37}$ the segregation of alloying elements, such as $\mathrm{Ni}, \mathrm{Al}, \mathrm{Mn}$, etc., was confirmed to derive from thermodynamic factors, ${ }^{27,38}$ and the segregation behaviors can change strain and chemical interactions at interfaces, resulting in the reduction of interface energy. ${ }^{39}$

Since point defects are tightly related to the microstructure evolution of steels, many studies were performed to reveal the interaction between point defects in body-centered cubic (bcc) Fe toward understanding the formation of precipitates. For example, the interactions between point solute atoms and intrinsic point defects in bcc Fe for extensive transition-metal alloying elements were investigated, ${ }^{40}$ and the stability of selfinterstitial atoms (SIA) and small SIA clusters in the vicinity of solute atoms in Fe matrix were also investigated. ${ }^{\mathbf{4 1}}$ The results of these researches revealed the basic rules of alloying element interaction and provided important information for larger scale simulations. In addition, there are also some attempts to use DFT calculations to directly understand and predict the formation of precipitates influenced by alloying elements. For example, it was revealed that, the reason that $\mathrm{Ca}$, $\mathrm{Ag}$ can increase the number density of precipitates in $\mathrm{Mg}-\mathrm{Zn}$ system is that these two elements can enhance the stability of G. P. zones in the very initial stage of formation of precipitates. ${ }^{42}$

For all above, it is confirmed that Mn can change the evolution of $\mathrm{Cu}$ precipitates and the mechanical properties of $\mathrm{Fe}-\mathrm{Cu}$ based steels. However, the investigation on $\mathrm{Fe}-\mathrm{Cu}$ based HSLA steels only reveals the response of hardness of alloys to $\mathrm{Mn}$ addition. Since the response of evolution of $\mathrm{Cu}$ precipitates to Mn addition is still not confirmed, how much the precipitates are responsible for the increase of hardness is not still identified. In another side, the DFT has become a powerful tool to understand the underlying mechanism in the evolution of precipitates. Therefore, we use both experiment and DFT calculations, to perform a systematic investigation on the influence of $\mathrm{Mn}$ on the evolution of $\mathrm{Cu}$ precipitates and its hardness, and try to reveal its mechanism at the atomic scale.

\section{Methods}

\subsection{Experiments}

The chemical compositions of $\mathrm{Fe}-1.0 \mathrm{Cu}(\mathrm{at} \%)$ and $\mathrm{Fe}-1.2 \mathrm{Cu}-$ 2.2Mn alloys are shown in Table 1 . To obtain the Cu precipitates with relative short experimental time, we choose to use alloys with relatively high contents of $\mathrm{Cu}$ and $\mathrm{Mn}$. The alloys were fabricated as described in ref. 7. After solution treatment at $900^{\circ} \mathrm{C}$ for $2 \mathrm{~h}$, we quench alloys to room temperature, and then perform heat treatments at $450^{\circ} \mathrm{C}$ for $0.25 \mathrm{~h}, 1 \mathrm{~h}, 2 \mathrm{~h}$, and $16 \mathrm{~h}$, respectively.

The hardness measurements are conducted on the polished surface of the samples by using Vickers hardness tester (HVS1000) with a load of $100 \mathrm{~g}$ for $10 \mathrm{~s}$, and at least seven indents are measured to obtain an average value for each sample. In order to prepare tip samples for APT, small rods with a crosssection of $0.5 \times 0.5 \mathrm{~mm}^{2}$ are cut out from the aged bulk steels. Subsequently, the tip samples are polished by the twostage electro-polishing method..$^{43}$ The APT experiments and analyses are performed on a local electrode atom probe (LEAP $4000 \mathrm{X} \mathrm{HR}$ ) at specimen temperature of $50 \mathrm{~K}$ with a target evaporation rate of $0.5 \%$, and the pulse fraction is $20 \%$ in an ultra-high vacuum of $\sim 10^{-11} \mathrm{~Pa}$. The voltage pulse repetition rate is set to be $200 \mathrm{kHz}$. Data reconstructions and analyses are conducted using the Integrated Visualization and Analysis Software (IVAS 3.6.8). The maximum separation method ${ }^{44}$ is employed to identify $\mathrm{Cu}$ precipitates, and we select the minimum solute atom number $\left(N_{\min }\right)$ of 20 , and the maximum separation distance $\left(d_{\max }\right)$ of $0.5 \mathrm{~nm}$.

\subsection{Calculations}

2.2.1 Details of DFT calculations. All of the density functional theory (DFT) ${ }^{45-47}$ calculations are performed by using the

Table 1 Chemical compositions of alloys (at\%)

\begin{tabular}{llllllllll}
\hline Alloy & $\mathrm{Cu}$ & $\mathrm{Mn}$ & $\mathrm{C}$ & $\mathrm{Si}$ & $\mathrm{P}$ & $\mathrm{S}$ & $\mathrm{Ni}$ & $\mathrm{Cr}$ & $\mathrm{Fe}$ \\
\hline $\mathrm{Fe}-\mathrm{Cu}$ & 1.2 & - & 0.0009 & 0.01 & 0.008 & 0.005 & 0.01 & 0.005 & Bal \\
Fe-Cu-Mn & 1.0 & 2.2 & - & - & 0.01 & 0.004 & 0.05 & - & Bal
\end{tabular}


Vienna Ab Initio Simulation Package (VASP) ${ }^{48}$ within the frame of generalized gradient approximation (GGA). ${ }^{49,50}$ We use the projector augmented wave method (PAW) to describe ionelectron interactions. ${ }^{51,52}$ We use the Monkhorst-Pack scheme for the Brillouin-zone integrations, ${ }^{53}$ and set plane wave energy cut-off as $280 \mathrm{eV}$. For $\mathrm{Cu}, \mathrm{Fe}$ and $\mathrm{Mn}$, the valence electrons considered are $3 d^{10} 4 p^{1}, 3 d^{7} 4 s^{1}$, and $3 d^{6} 4 s^{1}$, respectively.

\subsubsection{Strategy of describing the stability of defects and $\mathrm{Cu}$} cluster

A. Point defect. The point defect is tightly related to the initial nucleation and growth of $\mathrm{Cu}$ precipitates. The typical point defects in steels are mono-vacancy and self-interstitial atom (SIA). The stability of these point defects is critical to reveal the evolution mechanism of $\mathrm{Cu}$ precipitates. Here, we use formation energy to reflect the stability of the point defect. The formation energy of a mono-vacancy or SIA $\left(E_{\mathrm{Pd}}\right)$ can be computed by the following eqn (1):

$$
E_{\mathrm{Pd}}=E_{\mathrm{P}}-n E_{\mathrm{Fe}}
$$

where $E_{\mathrm{P}}$ is the total energy of supercell with a mono-vacancy or a SIA, $E_{\mathrm{Fe}}$ is the total energy per atom of perfect body-centered cubic (bcc) Fe crystal, $n$ is the number of atoms in the supercell used to accommodate defect or simulate perfect Fe matrix. For each equation, we use the same size supercell to perform calculation. The atom numbers of supercell with pure bcc Fe and supercell with solute atoms are both $n$, and atom numbers of supercells with a mono-vacancy and a SIA are $n-1$ and $n+1$, respectively.

The formation energy of SIA with a $M$ solute atom, (M@SIA, $\mathrm{M}=\mathrm{Cu}$ or $\mathrm{Mn}), E_{\mathrm{Pd}}(\mathrm{Fe}, \mathrm{M})$, can be computed by the following eqn (2):

$$
\left.E_{\mathrm{Pd}}(\mathrm{Fe}, \mathrm{M})=E_{\mathrm{Ps}}+n E_{\mathrm{Fe}}-\left(E_{\mathrm{Fe}}(\mathrm{M})+(n+1) E_{\mathrm{Fe}}\right)\right)
$$

where $E_{\mathrm{Ps}}$ is the total energy of supercell with a M@SIA, $E_{\mathrm{Fe}}(\mathrm{M})$ is the total energy of supercell with a substitutional $\mathbf{M}$ solute atom.

B. Frenkel pair. The formation energy of a Frenkel pair with mono-vacancy and pure Fe SIA $\left(E_{\mathrm{Fd}}\right)$ can be computed by the following eqn (3):

$$
E_{\mathrm{Fd}}=E_{\mathrm{M}}+E_{\mathrm{s}}-2 n E_{\mathrm{Fe}}
$$

where $E_{\mathrm{M}}$ and $E_{\mathrm{S}}$ are the total energies of the supercell with a mono-vacancy and the supercell with a SIA respectively.

The formation energy of a Frenkel pair with mono-vacancy and M@SIA ( $\left.E_{\mathrm{Fd}}(\mathrm{M} @ S I A)\right)$ can be computed by the following eqn (4):

$$
E_{\mathrm{Fd}}(\mathrm{M} @ \mathrm{SIA})=E_{\mathrm{M}}+E_{\mathrm{s}}^{\mathrm{M}}-\left(n E_{\mathrm{Fe}}+\left(E_{\mathrm{Fe}}(\mathrm{M})\right)\right.
$$

where $E_{\mathrm{s}}^{\mathrm{M}}$ is the total energy of supercell with a M@SIA.

$C$. The interaction of defect with solute $\mathrm{Cu}$. The binding energy between a point defect and a Cu atom $\left(\Delta E_{(\mathrm{D}, \mathrm{Cu})}\right)$ can be computed by the following eqn (5):

$$
\Delta E_{(\mathrm{D}, \mathrm{Cu})}=E_{\mathrm{D}, \mathrm{Cu}}+n E_{\mathrm{Fe}}-\left(E_{\mathrm{D}}+E_{\mathrm{Cu}}\right)
$$

where $E_{\mathrm{D}, \mathrm{Cu}}$ is the total energy of supercell with a defect D and a solute $\mathrm{Cu}$ atom, $E_{\mathrm{D}}$ is the total energy of supercell with a defect $\mathrm{D}$, and $E_{\mathrm{Cu}}$ is the total energy of supercell with a solute $\mathrm{Cu}$ atom.

$D$. Solute $\mathrm{Cu}$ cluster. The formation energy of $\mathrm{Cu}$ cluster $\left(E_{\mathrm{Clu}}\right)$ can be computed by the following eqn (6):

$$
\left.E_{\mathrm{Clu}}=\left(E_{\mathrm{C}_{\mathrm{tot}}}+\left(n_{\mathrm{Cu}}-1\right) n E_{\mathrm{Fe}}\right)-n_{\mathrm{Cu}} E_{\mathrm{Cu}}\right)
$$

where $E_{\mathrm{C}_{\text {tot }}}$ is the total energy of the supercell including a $\mathrm{Cu}$ cluster, $n_{\mathrm{Cu}}$ is the number of $\mathrm{Cu}$ atoms in $\mathrm{Cu}$ cluster.

The formation energy of $\mathrm{Cu}$ cluster with defects $\left(E_{\mathrm{Clu}, \mathrm{D}}\right)$, such as mono-vacancy, SIA and Mn@SIA, can be computed by the following eqn (7):

$$
E_{\mathrm{Clu}, \mathrm{D}}=E_{\mathrm{C}_{\mathrm{tot}}, \mathrm{D}}+n_{\mathrm{Cu}} n E_{\mathrm{Fe}}-\left(n_{\mathrm{Cu}} E_{\mathrm{Cu}}+E_{\mathrm{D}}\right)
$$

where $E_{\mathrm{C}_{\text {tot }}, \mathrm{D}}$ is the total energy of the supercell including a $\mathrm{Cu}$ cluster and a defect.

By considering the balance between the precision and computation efficiency, here, we use supercells with 64 atoms to compute the formation energy of point defects, and use supercells with 128 atoms to compute the formation energy of $\mathrm{Cu}$ clusters. Tests have been done to verify that these sizes of supercells are sufficient for calculating formation energies of point defects and small Cu clusters. We only use 3-atom clusters to explore the trend of the influence on the stability of $\mathrm{Cu}$ clusters in bcc Fe.

\section{The relationship between hardness and $\mathrm{Cu}$ precipitates}

\subsection{Age-hardening response}

The Vickers hardness values of the $\mathrm{Fe}-\mathrm{Cu}$ and $\mathrm{Fe}-\mathrm{Cu}-\mathrm{Mn}$ alloys as a function of aging time at $450{ }^{\circ} \mathrm{C}$ are shown in Fig. 1. The values of hardness of the $\mathrm{Fe}-\mathrm{Cu}$ and $\mathrm{Fe}-\mathrm{Cu}-\mathrm{Mn}$ alloys at the asquenched (AQ) state are $145 \mathrm{HV}$ and $195 \mathrm{HV}$ respectively, indicating that $\mathrm{Mn}$ can improve the hardness of $\mathrm{Fe}-\mathrm{Cu}$ alloy. The values of peak hardness of $\mathrm{Fe}-\mathrm{Cu}$ and $\mathrm{Fe}-\mathrm{Cu}-\mathrm{Mn}$ alloys are 225 and $235 \mathrm{HV}$, reflecting that the latter is slightly higher than the former. However, the hardness of $\mathrm{Fe}-\mathrm{Cu}-\mathrm{Mn}$ decreases

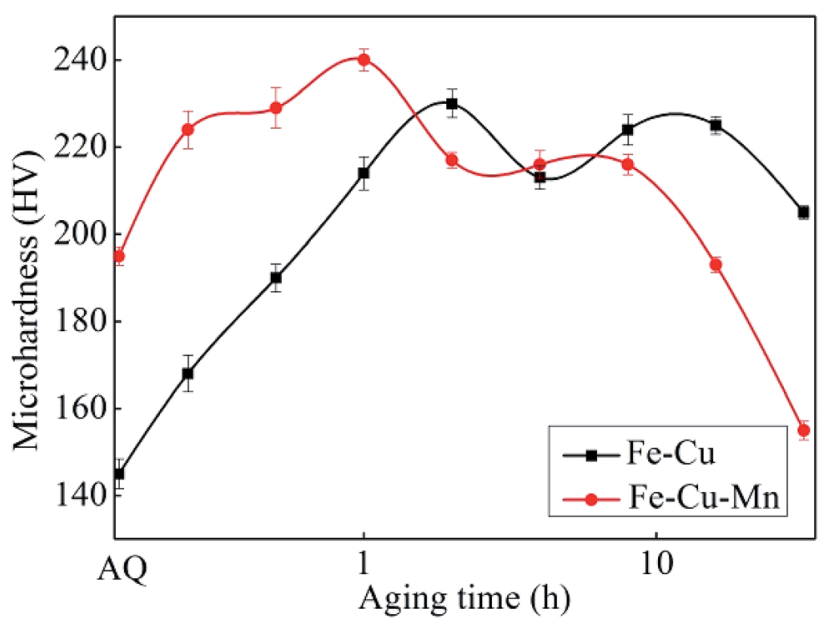

Fig. 1 The Vickers hardness for $\mathrm{Fe}-\mathrm{Cu}$ and $\mathrm{Fe}-\mathrm{Cu}-\mathrm{Mn}$ alloys aged at $450{ }^{\circ} \mathrm{C}$ after solid solution treatment at $900{ }^{\circ} \mathrm{C}$ for $2 \mathrm{~h}$. 
obviously after the peak value (i.e. after $1 \mathrm{~h}$ ); while the hardness of $\mathrm{Fe}-\mathrm{Cu}$ almost does not decrease after the peak value. These findings agree well with previous results. ${ }^{33}$

Fig. 2 shows the optical micrographs of two alloys at AQ and age-peak states. It is found that the addition of Mn does not transform ferrite into other phases in both alloys, and therefore $\mathrm{Fe}-\mathrm{Cu}-\mathrm{Mn}$ showing higher hardness than $\mathrm{Fe}-\mathrm{Cu}$ is not caused by phase transformation. However, the sizes of grains in $\mathrm{Fe}-\mathrm{Cu}-$ $\mathrm{Mn}$ are obviously smaller than those of $\mathrm{Fe}-\mathrm{Cu}$, and the hardening effect on $\mathrm{Fe}-\mathrm{Cu}-\mathrm{Mn}$ can be attributed to grain refinement induced by $\mathrm{Mn}$ addition.

To further understand the mechanism of $\mathrm{Mn}$ on the mechanical properties in $\mathrm{Fe}-\mathrm{Cu}$ alloy, we use APT to investigate the evolution of $\mathrm{Cu}$ precipitates. Fig. 3 displays the positions of individual $\mathrm{Cu}$ and $\mathrm{Mn}$ atoms for $\mathrm{Fe}-\mathrm{Cu}$ and $\mathrm{Fe}-\mathrm{Cu}-\mathrm{Mn}$ alloys aged at $450{ }^{\circ} \mathrm{C}$ for $0.25 \mathrm{~h}, 1 \mathrm{~h}, 2 \mathrm{~h}$ and $16 \mathrm{~h}$, respectively. The number density $\left(N_{\mathrm{v}}\right)$ and average radius $\left(R_{\mathrm{p}}\right)$ based on the above APT results are calculated and shown in Table 2. As seen in Fig. 3 and Table 2, it is found that the average radius of $\mathrm{Cu}$ precipitates in two alloys increases, and the number density first increases and then decreases.

After aging for $0.25 \mathrm{~h}$, we identify clearly that many Cu clusters have been formed from Fig. 3. However, it is difficult to identify Mn clusters in the atom maps. Therefore, as shown in Fig. 4, we present nearest neighbor distribution (NND) curve of Mn atoms for $\mathrm{Fe}-\mathrm{Cu}-\mathrm{Mn}$ alloys along with random distribution curve, and it shows that the NND curve of Mn slightly deviates from random distribution curve. It suggests that there is a slight trend of the clustering of $\mathrm{Mn}$ atoms in $\mathrm{Fe}-\mathrm{Cu}-\mathrm{Mn}$ after aging for $0.25 \mathrm{~h}$. A more careful survey on atom maps from 0.25 to $16 \mathrm{~h}$, we can confirm that $\mathrm{Mn}$ clusters overlap spatially with $\mathrm{Cu}$ clusters.

\subsection{Temporal evolution of $\mathrm{Cu}$ precipitates}

As shown in Table 2, after aging for $0.25 \mathrm{~h}$, the average radius $R_{\mathrm{p}}$ of $\mathrm{Cu}$ clusters are both $1.0 \mathrm{~nm}$, while the number density of $\mathrm{Cu}$ clusters in $\mathrm{Fe}-\mathrm{Cu}-\mathrm{Mn}$ alloy is 4 times than that in the $\mathrm{Fe}-\mathrm{Cu}$ alloy. It indicates that the addition of Mn increases the nucleation rate of $\mathrm{Cu}$ precipitates at the initial aging stage, which is responsible for the higher increment of hardness for $\mathrm{Fe}-\mathrm{Cu}-\mathrm{Mn}$ compared to $\mathrm{Fe}-\mathrm{Cu}$ as shown in Fig. 1.

Table 2 shows, during the aging time from 0.25 to $1 \mathrm{~h}$, the increase of number density of clusters for $\mathrm{Fe}-\mathrm{Cu}$ is more rapid than that for $\mathrm{Fe}-\mathrm{Cu}-\mathrm{Mn}$, which accounts for the increment of hardness for $\mathrm{Fe}-\mathrm{Cu}-\mathrm{Mn}$ is smaller than that for $\mathrm{Fe}-\mathrm{Cu}$. During the aging time from $1 \mathrm{~h}$ to $2 \mathrm{~h}$, the number density of clusters for $\mathrm{Fe}-\mathrm{Cu}$ still increases, while the number density of clusters for $\mathrm{Fe}-\mathrm{Cu}-\mathrm{Mn}$ begins to decrease and the size of clusters begins to increase, which accounts for that the hardness of the former still increases and the latter begins to decrease.

At the aging time of $16 \mathrm{~h}$, the number density of clusters for $\mathrm{Fe}-\mathrm{Cu}$ decreases to $2.2 \times 10^{23} \mathrm{~m}^{-3}$, and that for $\mathrm{Fe}-\mathrm{Cu}-\mathrm{Mn}$ decreases to $0.6 \times 10^{23} \mathrm{~m}^{-3}$. As shown in Fig. 5, there are still many smaller clusters observed in $\mathrm{Fe}-\mathrm{Cu}$ while almost large clusters with radius larger than $4.0 \mathrm{~nm}$ in $\mathrm{Fe}-\mathrm{Cu}-\mathrm{Mn}$. These findings account for that the hardness of $\mathrm{Fe}-\mathrm{Cu}$ decreases slightly, but the hardness of $\mathrm{Fe}-\mathrm{Cu}-\mathrm{Mn}$ decreases abruptly.

\section{The driving force for the formation of defects and Cu precipitates}

The nucleation and growth of precipitates are tightly related to the point defects in alloys, but it is difficult to be observed by
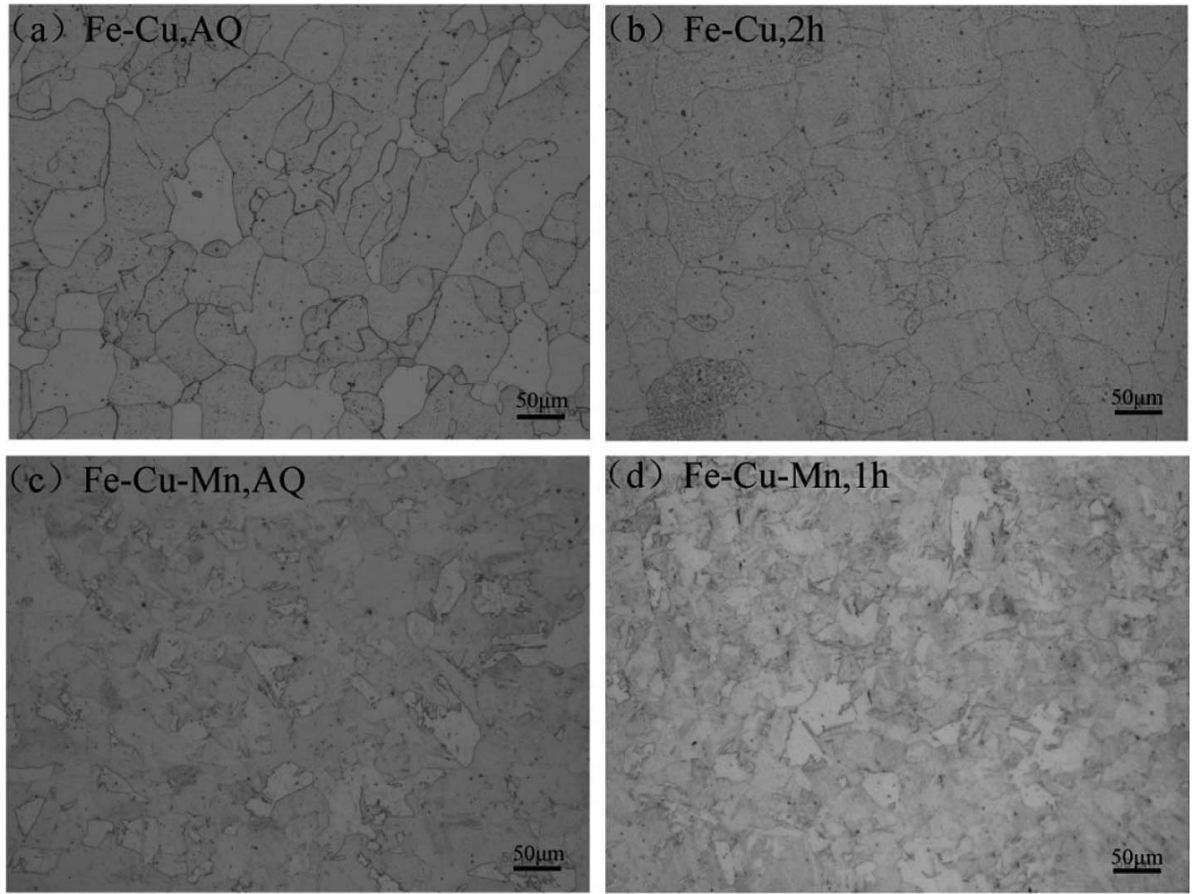

Fig. 2 Microstructures of the alloys: (a) as-quenched state of $\mathrm{Fe}-\mathrm{Cu}$; (b) the age-peak state of $\mathrm{Fe}-\mathrm{Cu}$; (c) as-quenched state of Fe-Cu-Mn; and (d) the age-peak state of $\mathrm{Fe}-\mathrm{Cu}-\mathrm{Mn}$. 


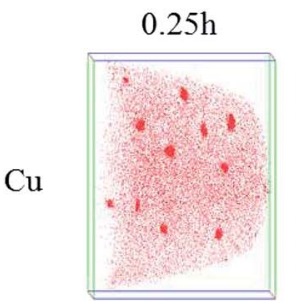

$1 \mathrm{~h}$

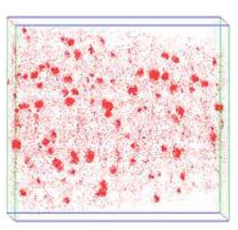

$2 \mathrm{~h}$

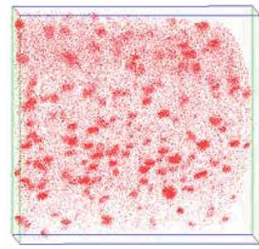

$\mathrm{Fe}-\mathrm{Cu}$
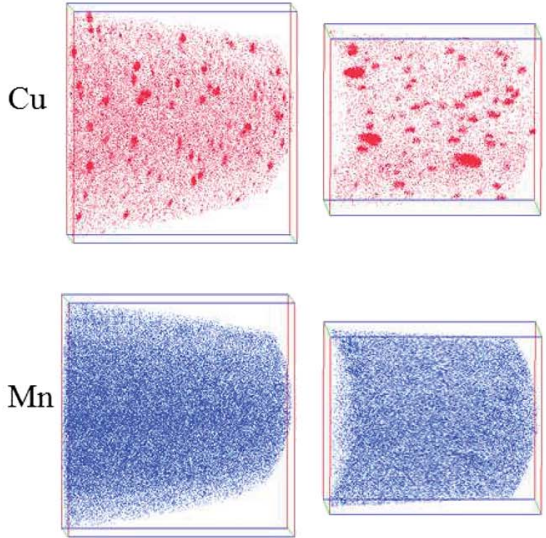
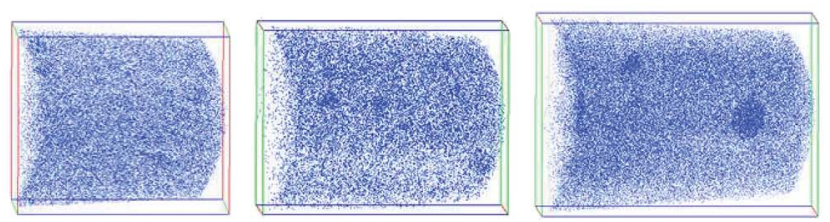

$16 \mathrm{~h}$

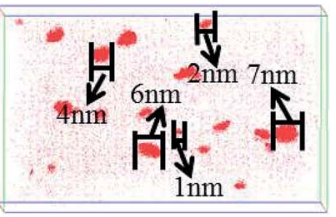

$20 \mathrm{~nm}$
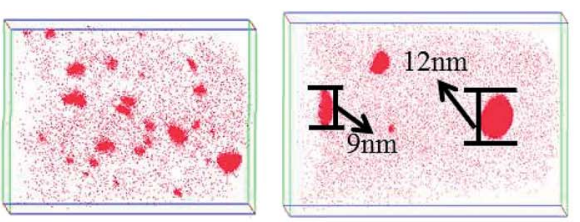

$\mathrm{Fe}-\mathrm{Cu}-\mathrm{Mn}$

Fig. 3 Three-dimensional atom maps of $\mathrm{Cu}$ and $\mathrm{Mn}$ of Fe-Cu and Fe-Cu-Mn alloys aged at $450{ }^{\circ} \mathrm{C}$ for $0.25 \mathrm{~h}, 1 \mathrm{~h}, 2 \mathrm{~h}, 16 \mathrm{~h}$.

Table 2 Average radius $\left(R_{\mathrm{p}}\right)$ and number density $\left(N_{\mathrm{v}}\right)$ of Cu precipitates in $\mathrm{Fe}-\mathrm{Cu}$ and $\mathrm{Fe}-\mathrm{Cu}-\mathrm{Mn}$ alloys

\begin{tabular}{llllll}
\hline & $R_{\mathrm{p}}(\mathrm{nm})$ & & & \multicolumn{2}{c}{$N_{\mathrm{v}}\left(\times 10^{23} \mathrm{~m}^{-3}\right)$} \\
\cline { 2 - 3 } & $\mathrm{Fe}-\mathrm{Cu}$ & $\mathrm{Fe}-\mathrm{Cu}-\mathrm{Mn}$ & & $\mathrm{Fe}-\mathrm{Cu}$ & $\mathrm{Fe}-\mathrm{Cu}-\mathrm{Mn}$ \\
\hline $0.25 \mathrm{~h}$ & $1.0 \pm 0.3$ & $1.0 \pm 0.3$ & & 1.2 & 4.9 \\
$1 \mathrm{~h}$ & $1.0 \pm 0.4$ & $1.0 \pm 0.5$ & & 8.1 & 8.8 \\
$2 \mathrm{~h}$ & $1.1 \pm 0.3$ & $1.3 \pm 0.6$ & & 17.4 & 5.7 \\
$16 \mathrm{~h}$ & $2.1 \pm 0.8$ & $3.7 \pm 0.9$ & & 2.2 & 0.6
\end{tabular}

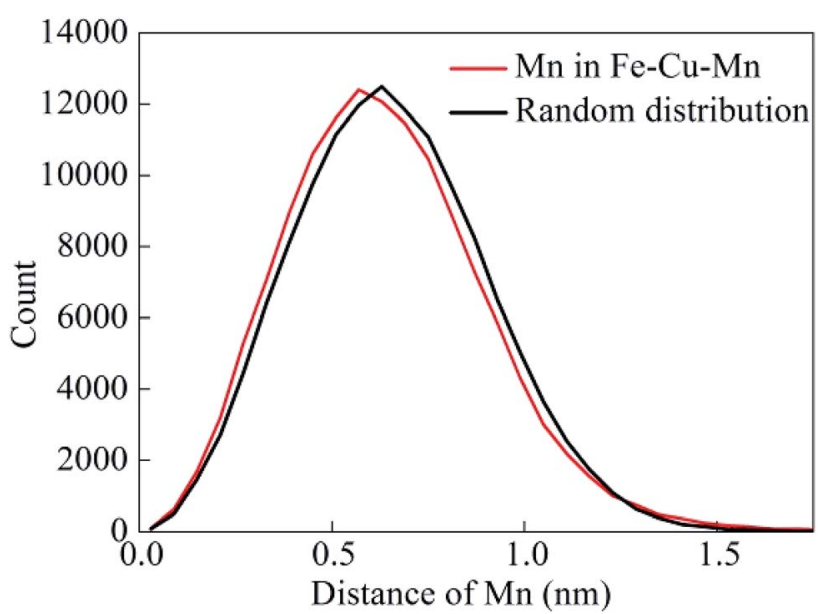

Fig. 4 Nearest neighbor distribution (NND) curve of $\mathrm{Mn}$ for Fe-Cu$\mathrm{Mn}$ alloy aged for $0.25 \mathrm{~h}$. experiments. Therefore, we use DFT total energy calculations to obtain the formation energies in $\mathrm{Fe}-\mathrm{Cu}$ and $\mathrm{Fe}-\mathrm{Cu}-\mathrm{Mn}$ systems, to reveal the thermal dynamical driving force for the formation of defects and $\mathrm{Cu}$ precipitates.

\subsection{Formation energy of point defects and $\mathrm{Cu}$ clusters}

Fig. 6(a) shows the atomic configuration of SIA. The formation energies of Schottky mono-vacancy and SIA in the $\alpha$-Fe are 2.19 and $1.78 \mathrm{eV}$ respectively. As shown in Table 3, we can find that
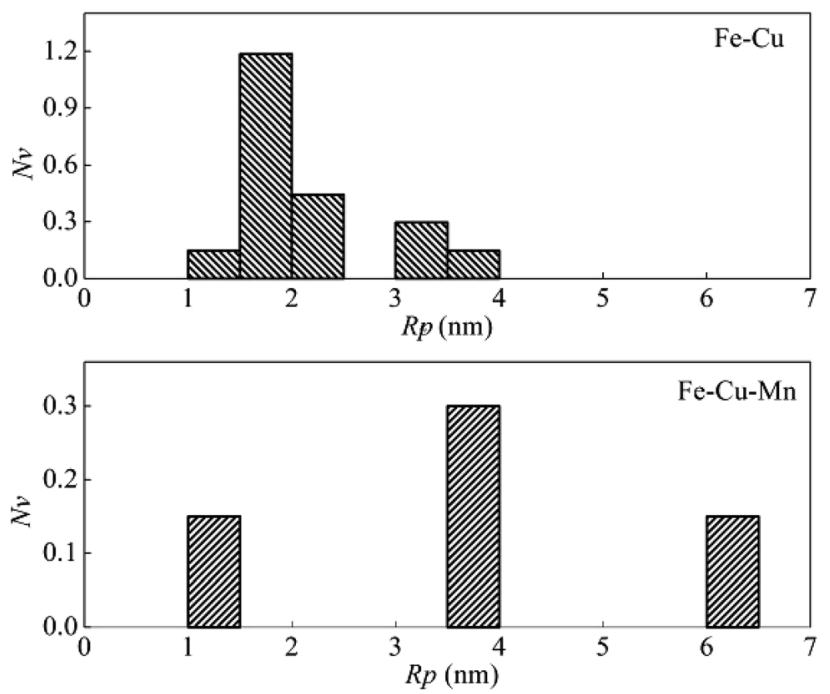

Fig. 5 The dependence of number density on the radius of $\mathrm{Cu}$ precipitates in Fe-Cu and Fe-Cu-Mn aged for $16 \mathrm{~h}$. 


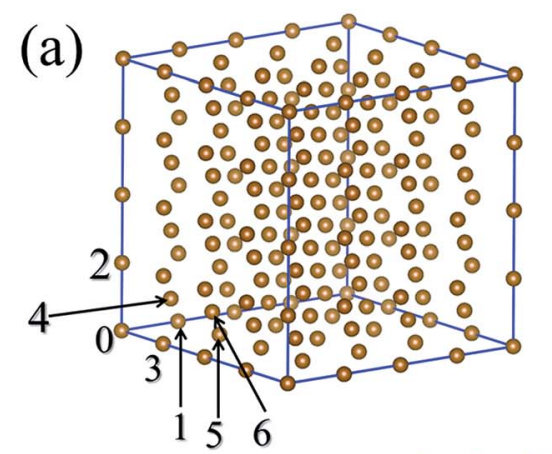

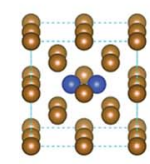

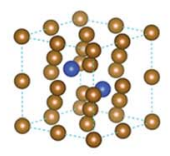

SIA[001] SIA[110]

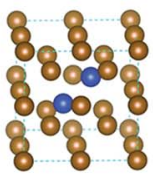

SIA[111]

- Fe atoms in BCC lattice

- Fe atoms in SIA

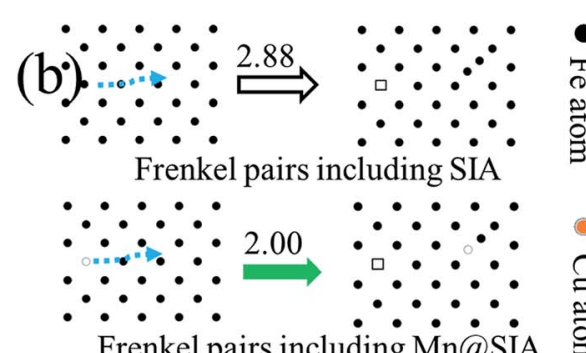

Frenkel pairs including Mn@SIA

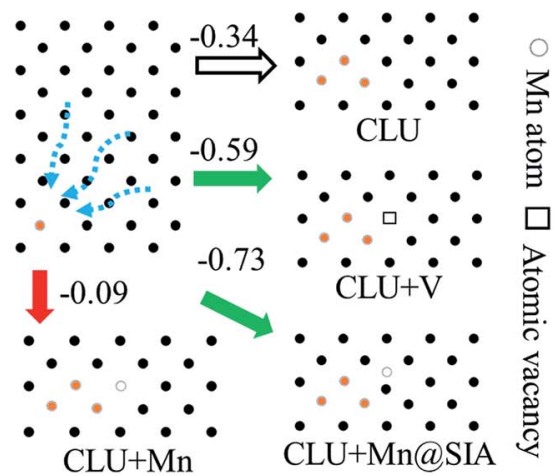

Fig. 6 (a) The top panel shows the atomic structure in a 128-atom supercell, and the numbers mark the positions of lattice used to be replaced by solute atoms or defects. The bottom panel displays the dumbbell structure of SIA atoms. (b) Illustration of the formation process of Frenkel pairs, Cu clusters (CLU) and Cu cluster with defects (CLU + V, CLU + Mn@SIA and CLU + Mn). The figures in left panel are the formation energies (in eV) of different structures.

Table 3 The formation energy (in eV) of Schottky SIA in $\alpha$-Fe

\begin{tabular}{llll}
\hline & SIA & Cu@SIA & Mn@SIA \\
\hline$[001]$ & 2.40 & 2.53 & 2.20 \\
{$[110]$} & 1.78 & 2.02 & 1.58 \\
{$[111]$} & 2.15 & 2.09 & 2.59
\end{tabular}

the SIA along the direction [110] is most favorable. Furthermore, we examine the formation energies of Cu@SIA and Mn@SIA. It is found that, for these structures, the SIA along [110] is still the most favorable. We find the formation energy of [110] Cu@SIA is higher than that of [110] SIA, indicating that the formation of self-interstitial atom for $\mathrm{Cu}$ is more difficult than that for Fe. In contrast, the formation energy of [110] Mn@SIA is lower than that of [110] SIA, indicating that the formation of self-interstitial atom for $\mathrm{Mn}$ is easier than that for Fe.

Table 4 shows that formation energies of Frenkel pair defects. The formation energy of [110] Mn@SIA + V is lower than

Table 4 The formation energy (in eV) of Frenkel pairs, SIA + monovacancy $(\mathrm{V})$ in $\alpha-\mathrm{Fe}$

\begin{tabular}{lllll}
\hline & $\frac{\text { SIA }}{}$ & & Cu@SIA & \\
& $E_{\mathrm{F}-\mathrm{d}}$ & & $E_{\mathrm{F}-\mathrm{d}}$ & \\
\hline$[001]$ SIA + V & 3.50 & 3.67 & $E_{\mathrm{F}-\mathrm{d}}$ \\
\hline$[110]$ SIA + V & 2.88 & 3.16 & 2.99 \\
{$[111]$ SIA + V } & 3.25 & 3.22 & 2.01 \\
\end{tabular}

that of [110] SIA $+\mathrm{V}$, which reflects that the presence of Mn atoms is much easier to induce the formation of Frenkel pairs. Therefore, in the Fe-Cu-Mn system, the formation of atomic vacancy is much easier via a way of Frenkel pairs compared to that in the $\mathrm{Fe}-\mathrm{Cu}$ system. The increase in the possibility of formation of vacancy in $\mathrm{Fe}-\mathrm{Cu}-\mathrm{Mn}$ system can promote the dynamics of precipitates, which accounts for that the growth of $\mathrm{Cu}$ precipitates in $\mathrm{Fe}-\mathrm{Cu}-\mathrm{Mn}$ is faster than that in $\mathrm{Fe}-\mathrm{Cu}$ as shown in Fig. 3 and Table 2. Hereafter, for the interaction of SIA

Table 5 The binding energies (in eV) between $\mathrm{Cu}$ and defects in $\alpha$-Fe. We place the $\mathrm{Cu}$ atom at the lattice site 1 in supercell on the top panel of Fig. $6(a)$, the position of defects in supercell are listed in below

\begin{tabular}{llc}
\hline Position & $\mathrm{Cu}$ atom $+\mathrm{V}$ & $\mathrm{Cu}$ atom $+\mathrm{Mn}$ \\
\hline 3 & -0.02 & 0.01 \\
4 & -0.27 & -0.004 \\
\hline
\end{tabular}

$\mathrm{Cu}$ atom $+[110]$ SIA

\begin{tabular}{llll} 
Position & $(110)$ SIA & $(101)$ SIA & $(011)$ SIA \\
\hline 3 & -0.19 & -0.12 & -0.12 \\
4 & -0.12 & -0.12 & -0.12 \\
\hline \multirow{2}{*}{ Position } & Cu atom + [110] Mn@SIA & \\
\cline { 2 - 4 } 3 & $(110)$ SIA & $(101)$ SIA & $(011)$ SIA \\
4 & -0.18 & -0.08 & -0.08 \\
& -0.003 & -0.003 & -0.003
\end{tabular}


Table 6 The formation energies (in eV) of Cu cluster with defects including mono-vacancy (CLU + V), solute substitutional Mn (CLU + Mn), selfinterstitial atoms (CLU + SIA) and self-interstitial Mn atoms (CLU + Mn@SIA). The positions of defects and the atoms in clusters are listed in below. The figures in bold indicate the formation energy lower than that of pure cluster, $-0.34 \mathrm{eV}$

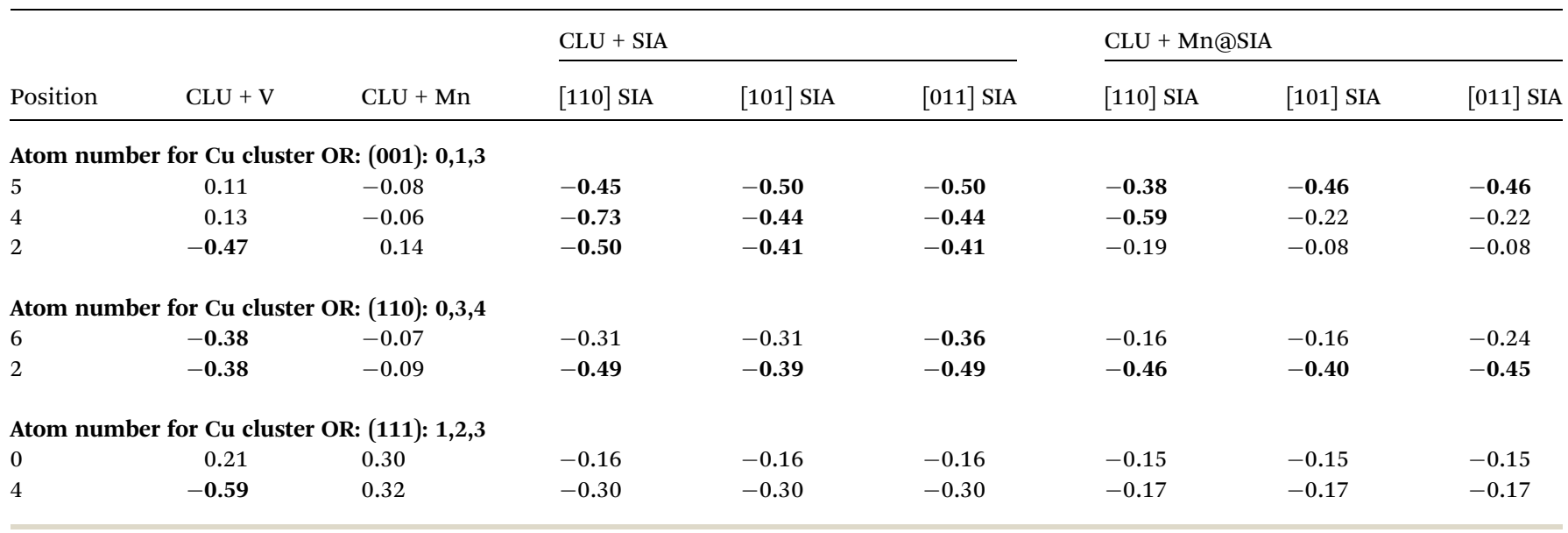

with other defects and $\mathrm{Cu}$ clusters, we only consider the most favorable structure of SIA, i.e., [110] SIA and [110] Mn@SIA.

\subsection{Interaction between $\mathrm{Cu}$ atoms and point defects}

The nucleation of $\mathrm{Cu}$ clusters at the very early stage is tightly related to the interaction between $\mathrm{Cu}$ atoms and point defects. Here, we compute the binding energy of dimer structures containing $\mathrm{Cu}$ atom and point defect in $\alpha$-Fe. The binding configuration between a $\mathrm{Cu}$ atom and other defect is embodied in a 128-atoms supercell that is shown in Fig. 6(a), and the positions of $\mathrm{Cu}$ atoms and defect are listed in Table 5. The lowest binding energy of $\mathrm{Cu}-\mathrm{V}$ dimer is $-0.27 \mathrm{eV}$, indicating that $\mathrm{Cu}$ atoms are preferred to bind with mono-vacancy. The lowest binding energy of $\mathrm{Mn}-\mathrm{Cu}$ dimer is $-0.004 \mathrm{eV}$, indicating that $\mathrm{Cu}$ atoms and $\mathrm{Mn}$ atoms almost have no attractive effect. Moreover, the lowest binding energy of $\mathrm{Cu}-\mathrm{SIA}$ and $\mathrm{Cu}-\mathrm{Mn} @ S I A$ are $-0.19 \mathrm{eV}$ and $-0.18 \mathrm{eV}$ respectively, indicating that the $\mathrm{Cu}$ atoms are preferred to bind with the SIA or Mn@SIA. Based on these findings, we can infer the trend that mono-vacancy, SIA and Mn@SIA can promote the gathering of $\mathrm{Cu}$ atoms to form clusters, but substitutional Mn solute atom cannot promote the gathering of $\mathrm{Cu}$ atoms.

\subsection{The interaction of point defect and $\mathrm{Cu}$ cluster}

To confirm the effect of point defects on the $\mathrm{Cu}$ gathering, we compute the formation energy of 3-Cu-atom cluster without and with point defects. The clusters are embodied in a 128-atoms supercell that is shown in Fig. 6(a), and the positions of $\mathrm{Cu}$ atoms and defect are listed in Table 6 . The formation energies of 3-Cu-atom clusters along (001), (110), and (111) are -0.11 , -0.34 and $0.002 \mathrm{eV}$, respectively. It indicates that the formation of $\mathrm{Cu}$ cluster in $\alpha$-Fe is thermodynamically favorable. The results also suggest that the (110) cluster is the most stable one, which is consistent with previous calculations. ${ }^{54}$ We also perform calculations on 4-Cu-atom clusters and also obtain the same trend on thermodynamics about $\mathrm{Cu}$ precipitates without and with defects. We here only use the result of a 3-Cu-atom cluster with defects under typical geometric structures to illustrate the interaction between $\mathrm{Cu}$ clusters and defects.

There are many configurations for the combination of a 3$\mathrm{Cu}$-atom cluster with atomic vacancy or substitutional $\mathrm{Mn}$ atom. We present some structures that the mono-vacancy or Mn is located at the first and second nearest position to the cluster plane. It is found the formation energy of the most stable cluster with mono-vacancy is $-0.59 \mathrm{eV}$, which is $0.25 \mathrm{eV}$ lower than that of the cluster without mono-vacancy. It indicates that the monovacancy can stabilize the $\mathrm{Cu}$ cluster, which results in the increase in formation probability of nucleation sites for $\mathrm{Cu}$ clusters. In contrast, the formation energy of the most stable cluster with substitutional $\mathrm{Mn}$ is $-0.09 \mathrm{eV}$, which is $0.25 \mathrm{eV}$ higher than that of the cluster without Mn, which indicates that substitutional Mn has no effect on stabilizing Cu clusters.

In Table 6, we also present the formation energies of complexes comprised of 3-Cu-atom cluster and SIA. We consider placing the SIA at three nearest sites from the cluster plane, and vary the orientation of cluster and the direction of SIA, and finally, we can obtain 42 configurations, whose formation energies are listed in Table 6. It is found that the most stable cluster with SIA has the formation energy of $-0.73 \mathrm{eV}$, which is $0.39 \mathrm{eV}$ lower than that of a pure $\mathrm{Cu}$ cluster. We also find that, among these structures, almost half of them with the formation energies are lower than that of pure $\mathrm{Cu}$ cluster. These findings show that both SIA and Mn@SIA increase the driving force of formation of $\mathrm{Cu}$ clusters.

\section{Discussions}

From the APT experiments, we find that the evolution of precipitate in $\mathrm{Fe}-\mathrm{Cu}-\mathrm{Mn}$ is much faster than that in $\mathrm{Fe}-\mathrm{Cu}$. At very initial stage from 0 to $0.25 \mathrm{~h}$, the number density of $\mathrm{Cu}$ clusters in $\mathrm{Fe}-\mathrm{Cu}-\mathrm{Mn}$ is much larger than that in $\mathrm{Fe}-\mathrm{Cu}$, which is the reason why the hardness increment of $\mathrm{Fe}-\mathrm{Cu}-\mathrm{Mn}$ is larger than that of $\mathrm{Fe}-\mathrm{Cu}$ during this period. At the aging peak, the hardness of $\mathrm{Fe}-\mathrm{Cu}-\mathrm{Mn}$ is slightly higher than that of $\mathrm{Fe}-\mathrm{Cu}$, but the number density of precipitates of the former is only half of 
the latter. It reflects that the hardening effect of Mn on alloys is mainly induced by the grain refinement and the increased number density of precipitates.

The number density of precipitates increases very fast in $\mathrm{Fe}-$ $\mathrm{Cu}-\mathrm{Mn}$ during aging. It takes two hours to reach the peak value for $\mathrm{Fe}-\mathrm{Cu}$, but only takes one hour for $\mathrm{Fe}-\mathrm{Cu}-\mathrm{Mn}$. Also, the increase in the size of precipitates for $\mathrm{Fe}-\mathrm{Cu}-\mathrm{Mn}$ is also much faster than that for $\mathrm{Fe}-\mathrm{Cu}$. At the aging time of $16 \mathrm{~h}$, the average diameter of precipitates in $\mathrm{Fe}-\mathrm{Cu}-\mathrm{Mn}$ is $7 \mathrm{~nm}$, which is obviously larger than that in $\mathrm{Fe}-\mathrm{Cu}, 4 \mathrm{~nm}$. Since the $\mathrm{Cu}$ precipitates larger than $5 \mathrm{~nm}$ will transform from bcc coherent precipitates into face center cubic precipitates structures and lose the hardening effect, ${ }^{55,56}$ the hardness of $\mathrm{Fe}-\mathrm{Cu}-\mathrm{Mn}$ at aging time of $16 \mathrm{~h}$ decreases very fast.

Based on computational results, we summary some important formation energies in Fig. 6(b), and we find that the presence of Mn causes that the formation of vacancy and SIA to become easier. First, the vacancy and SIA both can enhance the driving force of the formation of nucleation sites for $\mathrm{Cu}$ precipitates. Therefore, the presence of $\mathrm{Mn}$ will increase the formation possibility of vacancy and SIA and the nucleation rate of $\mathrm{Cu}$ precipitates. It accounts for the APT experiments, at the very initial aging stage, the number density of precipitates in $\mathrm{Fe}-\mathrm{Cu}-\mathrm{Mn}$ is much larger than that in $\mathrm{Fe}-\mathrm{Cu}$. Second, since $\mathrm{Mn}$ can reduce the formation energy of Frenkel pairs, the formation of mono-vacancy becomes easier; therefore $\mathrm{Mn}$ can increase the density of mono-vacancy in Fe matrix, which increases the diffusion of atoms and evolution of precipitates. Since Frenkel pairs can provide both SIA and monovacancy, it can influence both processes of nucleation and growth of $\mathrm{Cu}$ precipitates; therefore Frenkel pairs have a very large influence on the evolution of $\mathrm{Cu}$ precipitates.

For self-interstitial atoms (SIA), it is generally recognized that SIA extensively occurs in steels under irradiation. However, we emphasis that the possibility of $\mathrm{Mn}$ self-interstitial atoms (Mn@SIA) also could exist at a considerable concentration in steels under the condition of heat-treatment, even its concentration is definitely lower than that in steels under irradiation. There are two reasons that support this assumption: (I) the formation energy of Mn@SIA is much lower than any other M@SIA ( $\mathrm{M}=\mathrm{Fe}, \mathrm{Co}, \mathrm{Ni}, \mathrm{Cu}, \mathrm{Ti} . .$. , more than 20 types of element ${ }^{57}$ ). (II) The $\mathrm{Mn}$ can segregate at $\mathrm{Cu}$ precipitate in steels under both irradiation and heat treatment condition, ${ }^{\mathbf{1 , 1 6}}$ DFT calculation $^{38}$ shows that the segregation only occurs when Mn exists as self-interstitial atom. Therefore, a considerable content of Mn should exist in the form of self-interstitial atom in steels under heat treatment condition. Therefore, the formation of Frenkel pairs in steels under heat-treatment is reasonable.

In addition, based on our results from experiments and theoretical calculations, we also give some understanding of the formation of $\mathrm{Cu}$ precipitates in RPV steels with very low copper content under irradiation. The formation energy of Mn@SIA is lower than SIA, indicating that the displacement damage in $\mathrm{Fe}-$ $\mathrm{Cu}-\mathrm{Mn}$ is more serious than that in $\mathrm{Fe}-\mathrm{Cu}$. Moreover, since the copper content is very low and the RPV steels are far away from the over-aging state, the increase of Mn in RPV steels will increase the number density of precipitates, which is consistent with the experiment of RPV steels under irradiation. ${ }^{58,59}$

\section{Conclusion}

The evolution of $\mathrm{Cu}$ precipitates in $\mathrm{Fe}-1.2 \mathrm{Cu}$ (at\%) and $\mathrm{Fe}$ 1.0Cu-2.2Mn after aging at $450{ }^{\circ} \mathrm{C}$ are investigated experimentally. Moreover, the point defects and its influence on nucleation and growth of $\mathrm{Cu}$ precipitates are investigated by DFT calculations. The conclusions can be summarized as follows:

(1) By addition 2.2\% $\mathrm{Mn}$ into $\mathrm{Fe}-\mathrm{Cu}$ alloy, the peak hardness for the alloy only increases from 225 to $235 \mathrm{HV}$; and the slight increase in hardness derives from the grain refinement instead of the increase of the number density of precipitates.

(2) Besides grain refinement and solid solution strengthening, the addition of Mn also can increase the evolution rate of $\mathrm{Cu}$ precipitates. The effect of $\mathrm{Mn}$ on increasing the evolution rate of $\mathrm{Cu}$ precipitates is very obvious, and it can induce that the hardness of alloys decrease dramatically in the stage of over aging.

(3) DFT calculations reveal that the reason why Mn increases the nucleation rate is that $\mathrm{Mn}$ can increase the formation possibility of atomic vacancy and SIA. Both atomic vacancy and SIA can serve as nucleation sites for $\mathrm{Cu}$ precipitates, and therefore the nucleation centers of $\mathrm{Cu}$ precipitates in $\mathrm{Fe}-\mathrm{Cu}-\mathrm{Mn}$ at the very initial stage of aging should be much more than that in $\mathrm{Fe}-\mathrm{Cu}$. This point has also been confirmed by our APT experiments.

(4) The formation energy of a Frenkel pair in $\mathrm{Fe}-\mathrm{Cu}-\mathrm{Mn}$ is much lower than that in $\mathrm{Fe}-\mathrm{Cu}$, indicating that the formation of Frenkel pairs in the former is much easier than that in the latter. It results that a large number of atomic vacancies can be produced by the way of formation of Frenkel pairs in $\mathrm{Fe}-\mathrm{Cu}-$ $\mathrm{Mn}$. The increase of vacancies will promote the evolution rate of $\mathrm{Cu}$ precipitates. Therefore, the formation possibility of Frenkel pairs is responsible for the increase of the evolution rate of $\mathrm{Cu}$ precipitates in $\mathrm{Fe}-\mathrm{Cu}-\mathrm{Mn}$ at the stage of over aging.

(5) We also discuss the role of Mn in RPV that serves under irradiation condition, and point out that, based on calculated results, Mn will enhance the displacement damage in RPV steels.

To recap, we have revealed the role of the $\mathrm{Mn}$ on the $\mathrm{Cu}$ precipitates and their effects on hardness. It is confirmed that $\mathrm{Mn}$ can increase the evolution rate of $\mathrm{Cu}$ precipitates. Based on this point, one can use the effect of $\mathrm{Mn}$ on $\mathrm{Cu}$ precipitates reasonably when designs new alloys or estimates the service behavior of $\mathrm{Fe}-\mathrm{Cu}$ based alloys.

\section{Conflicts of interest}

There are no conflicts to declare.

\section{Acknowledgements}

This work was supported by National Key Research and Development Program of China (No. 2017YFB0703002, 2016YFB0700401), the State Key Lab of Rolling and Automation of Northeastern University Development Fund (No. 2016002), China Academy of Engineering Physics Joint Funds of National Natural Science Foundation of China (U1530115), 
Science and Technology Commission of Shanghai Municipality (15ZR1416000), Special Funding for the Development of Science and Technology of Shanghai Ocean University (No. A2-0203-00-100231) and Shanghai Pujiang Program (No. 18PJ1404200). High performance computing resources are provided by the Ziqiang Supercomputer Centre at Shanghai University.

\section{References}

1 D. Isheim, M. S. Gagliano, M. E. Fine and D. N. Seidman, Acta Mater., 2006, 54, 841-849.

2 D. Isheim, R. P. Kolli, M. E. Fine and D. N. Seidman, Scr. Mater., 2006, 55, 35-40.

3 R. P. Kolli, Z. G. Mao and D. N. Seidman, Microsc. Microanal., 2007, 13, 272-284.

4 R. P. Kolli and D. N. Seidman, Acta Mater., 2008, 56, 20732088.

5 Z. B. Jiao, J. H. Luan, W. Guo, J. D. Poplawsky and C. T. Liu, Mater. Res. Lett., 2017, 5, 562-568.

6 Z. B. Jiao, J. H. Luan, W. Guo, J. D. Poplawsky and C. T. Liu, Acta Mater., 2016, 120, 216-227.

7 Q. Shen, X. Y. Xiong, T. Li, H. Chen, Y. M. Cheng and W. Q. Liu, Mater. Sci. Eng., A, 2018, 723, 279-286.

8 Z. B. Jiao, J. H. Luan, M. K. Miller, Y. W. Chung and C. T. Liu, Mater. Today, 2016, 20, 142-154.

9 R. P. Kolli, Z. G. Mao and D. N. Seidman, Appl. Phys. Lett., 2007, 91, 241903.

10 J. C. Yan, H. W. Xu, X. W. Zuo, T. Jia and E. G. Wang, Mater. Sci. Eng., A, 2019, 739, 225-234.

11 S. P. Shu, P. B. Wells, N. Almirall, G. R. Odette and D. D. Morgan, Acta Mater., 2018, 157, 298-306.

12 D. Isheim, M. S. Gagliano, M. E. Fine and D. N. Seidman, Metall. Mater. Trans. A, 2016, 47, 3860-3872.

13 Y. R. Wen, A. Hirata, Z. W. Zhang, T. Fujita, C. T. Liu, J. H. Jiang and M. W. Chen, Acta Mater., 2013, 61, 2133-2147.

14 Z. M. Wang, H. Li, Q. Shen, W. Q. Liu and Z. Y. Wang, Acta Mater., 2018, 156, 158-171.

15 Z. M. Wang, X. L. Fang, H. Li and W. Q. Liu, Microsc. Microanal., 2017, 23, 340-349.

16 M. K. Miller and K. F. Russell, J. Nucl. Mater., 2007, 371, 145160.

17 Q. Xu, T. Yokotani, T. Onitsuka and K. Sato, J. Nucl. Mater., 2018, 512, 314-319.

18 L. T. Belkacemi, E. Meslin, B. Decamps, B. Radiguet and J. Henry, Acta Mater., 2018, 161, 61-72.

19 S. P. Shu, N. Almirall, P. B. Wells, T. Yamamoto, G. R. Odette and D. D. Morgan, Acta Mater., 2018, 157, 72-82.

20 S. C. Glade, B. D. Wirht, G. R. Odettes, P. A. Kumar, P. A. Sterne and R. H. Howell, Philos. Mag., 2005, 85, 629639.

21 M. K. Miller, B. D. Wirth and G. R. Odette, Mater. Sci. Eng., A, 2003, 353, 133-139.

22 S. Kobayashi, H. Kikuchi, S. Takahashi, Y. Kamada, K. Ara, T. Yamamoto, D. Klingensmith and G. R. Odette, J. Nucl. Mater., 2009, 384, 109-114.
23 S. Kobayashi, H. Kikuchi, S. Takahashi, Y. Kamada, K. Ara, T. Yamamoto, D. Klingensmith and G. R. Odette, Philos. Mag., 2007, 87, 4047-4058.

24 M. Lambrecht, L. Malerba and A. Almazouzi, J. Nucl. Mater., 2008, 378, 282-290.

25 E. Meslin, M. Lambrecht, M. Hernández-Mayoral, F. Bergner, L. Malerba, P. Pareige, B. Radiguet, A. Barbu, D. Gómez-Briceño, A. Ulbricht and A. Almazouzi, J. Nucl. Mater., 2010, 406, 73-83.

26 R. Schnitzer, M. Schober, S. Zinner and H. Leitner, Acta Mater., 2010, 58, 3733-3741.

27 Y. P. Xie and S. J. Zhao, Comput. Mater. Sci., 2012, 63, 329335.

28 Z. B. Jiao, J. H. Luan, M. K. Miller and C. T. Liu, Acta Mater., 2015, 97, 58-67.

29 Z. Jiao, S. Taller, K. Field, G. M. Yeli, M. P. Moody and G. S. Was, J. Nucl. Mater., 2018, 504, 122-134.

30 G. M. Yeli, M. A. Auger, K. Wilford, G. D. W. Smith, P. A. J. Bagot and M. P. Moody, Acta Mater., 2017, 125, 38-49.

31 A. Barashev, S. Golubov, D. Bacon, P. E. J. Flewitt and T. A. Lewis, Acta Mater., 2004, 52, 877-886.

32 R. Shabadi, R. Taillard, B. Radiguet, J. D. Baerdemaeker and E. Leunis, Solid State Phenom., 2011, 172-174, 297-302.

33 I. Gorbatov, I. K. Razumov, Y. N. Gornostyrev, V. I. Razumovskiy, P. A. Korzhavyi and A. V. Ruban, Phys. Rev. B: Condens. Matter Mater. Phys., 2013, 88, 174113.

34 W. X. Song and S. j. Zhao, Phys. Chem. Chem. Phys., 2014, 16, 7222-7230.

35 Y. F. Wen and J. Sun, J. Appl. Phys., 2012, 111, 053517.

36 I. Gorbatov, S. V. Okatov, Y. N. Gornostyrev, P. A. Korzhavyi and A. V. Ruban, Phys. Met. Metallogr., 2013, 114, 642-653.

37 J. Z. Liu, A. van de Walle, G. Ghosh and M. Asta, Phys. Rev. B: Condens. Matter Mater. Phys., 2005, 72, 144109.

38 Y. P. Xie and S. J. Zhao, J. Nucl. Mater., 2014, 445, 43-49.

39 Y. P. Xie and S. J. Zhao, Comput. Mater. Sci., 2011, 50, 25862591.

40 P. Olsson, T. P. C. Klaver and C. Domain, Phys. Rev. B: Condens. Matter Mater. Phys., 2010, 81, 054102.

41 C. S. Becquart, H. R. Ngayam, P. Olsson and C. Domain, J. Nucl. Mater., 2018, 500, 92-109.

42 H. T. Ma, R. Yuan, Y. P. Xie, H. Gao, L. J. Hu, X. D. Li, Y. C. Qian and Z. H. Dai, Acta Mater., 2018, 147, 42-50.

43 M. K. Miller, K. Michael and R. G. Forbes, Atom probe tomography, Springer, US, 2000.

44 M. K. Miller and R. G. Forbes, Introduction to atom probe tomography, Springer, US, 2014.

45 P. Hohenberg and W. Kohn, Phys. Rev., 1964, 136, 864-871. 46 W. Kohn and L. J. Sham, Phys. Rev., 1965, 137, 1697-1705.

47 R. O. Jones and O. Gunnarsson, Rev. Mod. Phys., 1989, 61, 689-746.

48 W. Dong, G. Kresse, J. Furthmyüller and J. Hafner, Phys. Rev. B: Condens. Matter Mater. Phys., 1996, 54, 2157-2166.

49 Y. Wang and J. P. Perdew, Phys. Rev. B: Condens. Matter Mater. Phys., 1991, 44, 13298-13307.

50 J. P. Perdew, J. A. Chevary, S. H. Vosko, K. A. Jackson, M. R. Pederson, D. J. Singh and C. Fiolhais, Phys. Rev. B: Condens. Matter Mater. Phys., 1993, 46, 6671-6687. 
51 G. Kresse and D. Joubert, Phys. Rev. B: Condens. Matter Mater. Phys., 1999, 59, 1758-1775.

52 P. E. Blöchl, Phys. Rev. B: Condens. Matter Mater. Phys., 1994, 50, 17953-17979.

53 H. J. Monkhorst and J. D. Pack, Phys. Rev. B: Solid State, 1976, 13, 5188-5192.

54 H. Choi, K. Chiho and Y. C. Chung, J. Appl. Phys., 2009, 106, 083910.

55 J. H. Shim, Y. W. Cho, S. C. Kwon, W. W. Kim and B. D. Wirth, Appl. Phys. Lett., 2007, 90, 021906.
56 Z. Z. Chen, N. Kioussis and N. Ghoniem, Phys. Rev. B: Condens. Matter Mater. Phys., 2009, 80, 184104.

57 P. Olsson, T. P. C. Klaver and C. Domain, Phys. Rev. B: Condens. Matter Mater. Phys., 2010, 81, 054102.

58 S. Kobayashi, H. Kikuchi, S. Takahashi, K. Chiba, Y. Kamada and K. Ara, Philos. Mag., 2007, 87, 4047-4058.

59 M. K. Miller, K. F. Russell, M. A. Sokolov and R. K. Nanstad, J. Nucl. Mater., 2007, 361, 248-261. 